\title{
Cemento-ossifying fibroma of the mandible: Presentation of a case and review of the literature
}

\author{
Javier Silvestre-Rangil ${ }^{1}$, Francisco Javier Silvestre ${ }^{2}$, Juan Requeni-Bernal ${ }^{1}$ \\ ${ }^{1}$ Odontólogo. \\ ${ }^{2}$ Profesor titular del Departamento de Estomatología de la Universidad de Valencia- Jefe de la Unidad de Estomatología del \\ Hospital Universitario Dr- Peset (Valencia)
}

Correspondence:

Hospital Universitario Dr. Peset

Unidad de Estomatología

Edificio de Consultas Externas

C/ Juan de Garay s/n

46017 - Valencia (Spain)

Silvestre-Rangil J, Silvestre FJ, Requeni-Bernal J. Cemento-ossifying fibroma of the mandible: Presentation of a case and review of the literature. J Clin Exp Dent. 2011;3(1):e66-9.

http://www.medicinaoral.com/odo/volumenes/v3i1/jcedv3i1p66.pdf

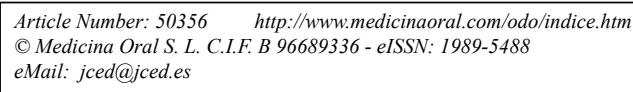

\begin{abstract}
Introduction: Cemento-ossifying fibroma is a benign fibro-osseous maxillary tumor belonging to the same category as fibrous dysplasia and cement-ossifying dysplasia. The aim of present study was report a case of cement-ossifying mandibular fibroma and offers a review of the literature on this disorder.

Case report: A 41-year-old woman presented for conventional dental treatment. A control panoramic X-ray study revealed a rounded, mixed-type image in the mandible, located in the periapical zone from tooth 4.3 to 3.3. The patient presented no symptoms and had no medical history of interest. A sample of the lesion was obtained for histopathological study, which yielded a definitive diagnosis of cemento-ossifying fibroma.

Discussion: The World Health Organization classifies cemento-ossifying fibroma as a fibro-osseous neoplasm included among the non-odontogenic tumors derived from the mesenchymal blast cells of the periodontal ligament, with a potential to for fibrous tissue, cement and bone, or a combination of such elements. These are slow-growing lesions, and are more frequent in women between the third and fourth decades of life. Although the underlying cause is not known, there have been reports of past trauma in the area of the lesion. Due to the good delimitation of the tumor, surgical removal and curettage is the treatment of choice.
\end{abstract}

Key words: Ossifying fibroma, cemento-ossifying fibroma, benign fibro-osseous lesions. 


\section{Introduction}

Cemento-ossifying fibroma is a benign fibro-osseous maxillary tumor belonging to the same category as fibrous dysplasia and cement-ossifying dysplasia (1). It is most commonly seen between the third and fourth decades of life (2-6), and is more frequent in women than in men (4:1). The most common location is the mandible, with $70-90 \%$ of all cases $(1,2)$. Clinically, these tumors manifest as a slow-growing intrabony mass that is normally well delimited and asymptomatic - though over time the lesion may become large enough to cause facial deformation (3).

Radiologically, cemento-ossifying fibroma shows a number of patterns depending on the degree of mineralization of the lesion. The latter manifests as a well delimited unilocular lesion containing variable amounts of radiopaque material (1-6).

Histologically, these tumors are composed of well vascularized fibrocellular tissue with the capacity to form immature bone trabeculae and cementoid formations, though these findings are not specific of the lesion and can also be seen in fibrous dysplasias (4). A definitive diagnosis therefore requires correlation of the clinical, radiological and histological findings (5).

Treatment comprises surgical resection of the lesion with enucleation and curettage of the bone bed $(2,6)$. The aim of present study was report a case of cement-ossifying mandibular fibroma and offers a review of the literature on this disorder.

\section{Case Report}

A 41-year-old woman presented for conventional dental treatment. A control panoramic X-ray study (Fig. 1) revealed a rounded, mixed-type image in the mandible, located in the periapical zone from tooth 4.3 to 3.3. The patient reported having suffered trauma in that same area years ago. She presented no symptoms, had no medical history of interest, and reported no toxic habits or drugs use.

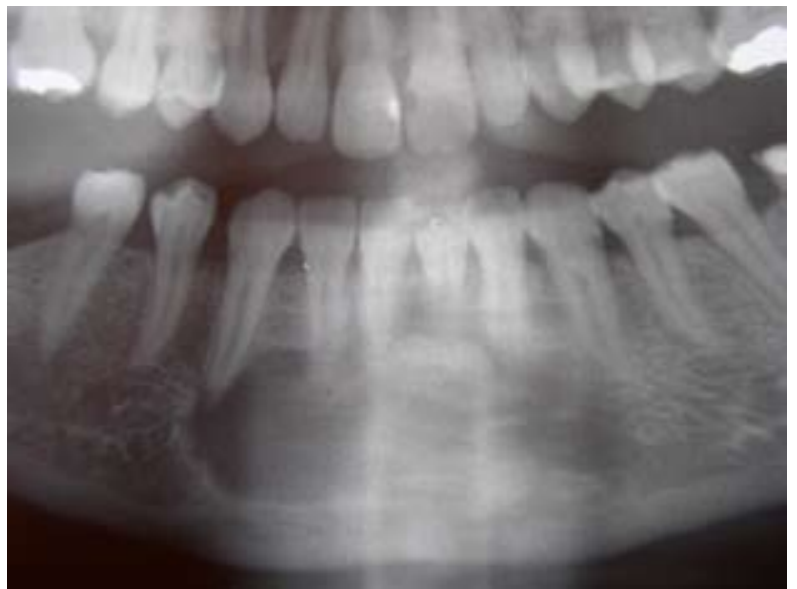

Fig. 1. Magnified panoramic X-ray view showing the initial lesion.
Oral exploration revealed the presence of a number of small caries and fillings in the posterior teeth, and some molars were missing $(3.6,4.6,4.7)$. The oral mucosa was normal, and the teeth in the lesion zone (between both lower canines) showed no alterations. Pulp vitality of the teeth adjacent to the lesion proved positive.

The radiological study showed no dental displacement. In addition to the panoramic X-ray study, we requested a mandibular computed tomography scan, which revealed a rounded and elongated osteolytic lesion located between the lower canines. Axial imaging showed the lesion to cause thinning and bulging of the anterior vestibular cortical layer, which was ruptured at some point (Fig. 2). Likewise, the core region of the lesion showed a series of rounded radiopaque images.

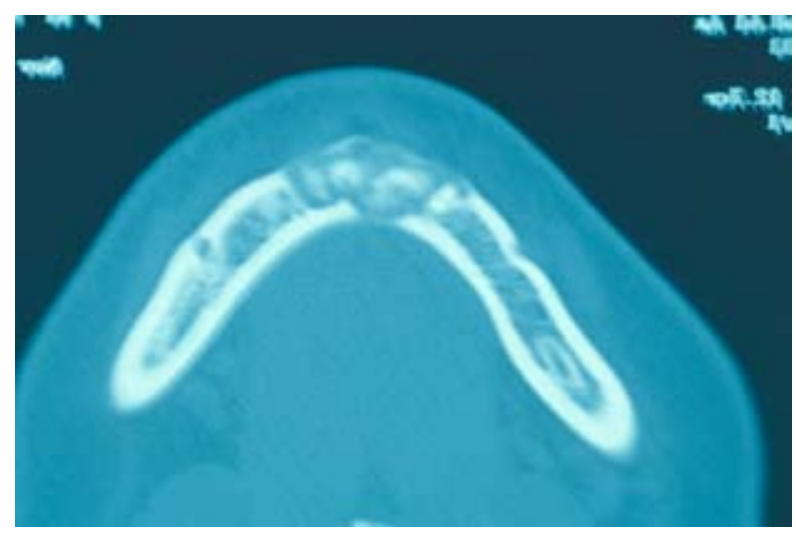

Fig. 2. Axial computed tomography scan showing an osteolytic zone containing central radiopaque images. Also note the thinning and rupture of the vestibular cortical layer.

A sample of the lesion was obtained for histopathological study, which revealed the presence of a fusocellular tumor containing calcifications with concentric and acellular mineralization at the center (cementoid type), and other areas presenting recently formed osteoid with peripheral osteoblasts and signs of progressive calcification (Fig. 3). There were no atypias or mitotic figures. The definitive diagnosis was cemento-ossifying fibroma.

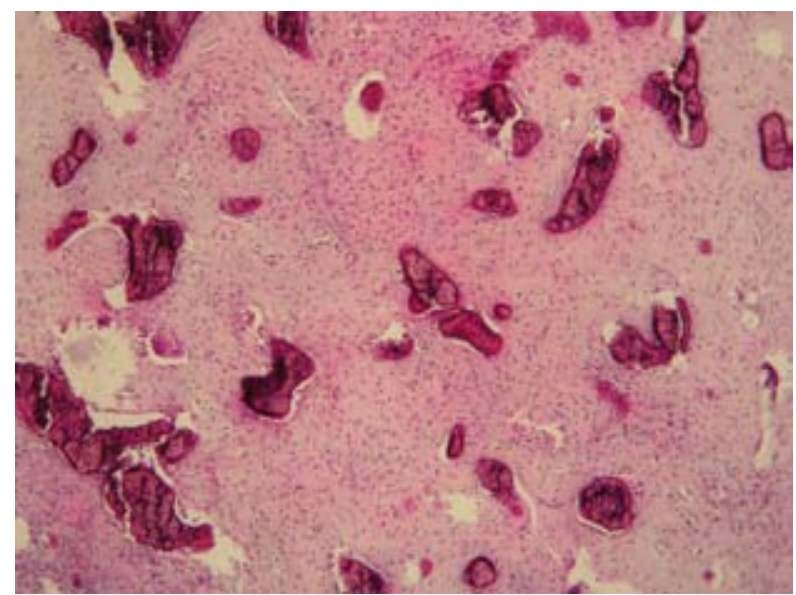

Fig. 3. Histological view showing a fibrous stroma with calcifications and osteoid material. 
Complete surgical removal of the lesion was carried out under infiltrating local anesthesia, raising a mucoperiosteal flap and performing ostectomy to gain access to the lesion. The bone bed was subjected to curettage.

The postoperative course was favorable, and one year later the patient reported no discomfort in the zone. A control panoramic X-ray study confirmed good bone regeneration in the zone.

\section{Discussion}

Cemento-ossifying fibroma is a benign fibro-osseous maxillary tumor (6). It is a slow-growing lesion most often seen in women between the third and fourth decades of life. While one-half of all cases are asymptomatic, the growth of the tumor over time may lead to facial asymmetry, with the appearance of a mass causing discomfort or mandibular expansion, and the possible displacement of dental roots $(2,7)$. In our case the lesion was casually identified on occasion of a panoramic X-ray study.

Although the underlying cause is not known, there have been reports of past trauma in the area of the lesion (8). In coincidence with the data found in the literature, our patient reported having suffered trauma in the affected zone years ago. This points to trauma as a possible triggering factor in some presentations of the lesion, postulating the latter as representing a connective tissue reaction rather than a genuine neoplasm (9).

The World Health Organization classifies cemento-ossifying fibroma as a fibro-osseous neoplasm included among the non-odontogenic tumors derived from the mesenchymal blast cells of the periodontal ligament, with a potential to for fibrous tissue, cement and bone, or a combination of such elements $(1,7)$. However, there is controversy over such an origin, since tumors of similar histology have been reported in bone lacking periodontal ligament and not located in the maxillary region, such as ethmoid bone, frontal bone or even long bones of the body (cementiform fibrous dysplasia)(10-14).

Clinically, the tumor tends to present as a slow-growing intrabony mass most often located in the region of the mandibular premolars and molars and in the ascending ramus - in contrast to the anterior mandibular location of our case. The growth is usually asymptomatic, though there may be a degree of root reabsorption or displacement of neighboring teeth $(2,6,8)$. These phenomena were not noted in our patient. There have been reports of more aggressive lesions characterized by rapid and extensive growth, capable of causing mandibular fractures, and multiple lesions have also been documented. Likewise, a more aggressive juvenile form has been described as juvenile cemento-ossifying fibroma $(1,15)$.

Radiologically, these tumors may present a number of patterns depending on their degree of mineralization (6). Two basic patterns have been defined: one characterized by the presence of a unilocular or multilocular radio- transparent image, and another showing mixed density due to a variable internal amount of radiopaque material $(1,2)$. The margins of the lesion are relatively well defined and present a peripheral osteocondensation zone (1). The fibroma is of concentric appearance within the medullary zone of the bone, and the cortical layers are preserved (1). In some cases the lesions are seen to be associated to root reabsorption and displacement of the roots of the neighboring teeth (6). In our case a mixed image was observed on the computed tomography scan, with peripheral osteolysis and internal radiopaque areas, and bulging of the vestibular cortical bone.

The histological study shows the presence of generally hypercellular fibrous tissue with the occasional presence of islands of bone tissue or cementiform calcifications $(1,6)$. Within the fibrous stroma we observe mineralized tissue masses of basophilic appearance, corresponding to osteoid material or cement (2), distributed throughout the lesion to one degree or other, and accompanied by dystrophic calcifications with darker or basophilic staining characteristics $(2,6)$. The morphology is benign, with very little proliferative activity and the absence of atypias or necrosis (2).

The differential diagnosis with fibrous dysplasia - particularly with the cementifying variant - is complicated, since the morphology is very similar in both cases. A definitive diagnosis is thus established upon also considering the clinical and radiological findings. Ossifying fibroma always presents well defined margins. Several sections of the sample must be carefully examined, since the identifying histopathological features are sometimes not observed in each and every portion of the tumor thus leading to possible diagnostic error. Other conditions to be taken into account are lesions appearing as a mixed periapical image such as calcifying odontogenic cysts or cementoblastomas, which are seen to be associated to the roots of vital permanent teeth. Likewise, focal cemento-osseous dysplasia appears as a radiotransparency associated to the dental apexes, and in more advanced stages presents extensive radiopaque areas surrounded by a radiotransparent halo $(1,2,6)$. Since our patient had a history of trauma in the affected zone, consideration is likewise required of other lesions that can also be associated with antecedents of trauma, such as central giant cell granulomas. However, although there are radiotransparent zones due to such lesions, no radiopaque areas are seen of multilocular appearance in the course of their evolution.

Due to the good delimitation of the tumor, surgical removal and curettage is the treatment of choice $(2,3)$. In the case of very large lesions with important tissue ablation, the challenge is to replace the affected tissue. The prognosis is usually good, since recurrences are not frequent. This was confirmed in our case, since repair of the affected area was seen to be correct one year after 
treatment - though longer follow-up is required.

\section{References}

1. Liu Y, Wang H, You M, Yang Z, Miao J, Shimizutani K et al. Ossifying fibromas of the jaw bone: 20 cases. Dentomaxillofac Radiol. 2010;39:57-63.

2. Sanchis JM, Peñarrocha M, Balaguer JM, Camacho F. Fibroma cemento-osificante mandibular:Presentación de dos casos y revisión de la literatura. Med Oral 2004; 9:69-73.

3. Pérez-García S, Berini-Aytés L, Gay-Escoda C. Fibroma osificante maxilar: Presentación de un caso y revisión de la literatura. Med Oral 2004; 9:333-9.

4. Eversole LR, Leider AS, Nelson K. Ossifying fibroma. a clinicopathologic study of sixty-four cases. Oral Surg Oral med Oral Pathol 1985; 60:505-11.

5. Martín-Granizo R, Sánchez-Cuellar LA, Falahat F. Cemento-ossifying fibroma of the upper gingivae. Otolaryngol Head Neck Surg $2000 ; 122: 775$.

6. Galdeano-Arenas M, Crespo-Pinilla JI, Álvarez-Otero R, EspesoFerrero A, Verrier-Hernández A. Fibroma cemento-osificante gingival mandibular. presentación de un caso. Med Oral 2004; 9:176-9.

7. Ong AH, Siar CH. Cemento ossifying fibroma with mandibular fracture. Case report in a young patient. Aust Dent J 1998; 43:229-33.

8. Brademann G, Werner JA, Janig U, Mehdorn HM, Rudert H. Cemento-ossifying fibroma of the petromastoid region: case report and review of the literature. J Laryngol Otol 1997; 111:152-5.

9. Feller L, Buskin A, Raubenheimer EJ. Cemento-ossifying fibroma: case report and review of the literature. J Int Acad Periodontol 2004 ; $6: 131-5$.

10. Jung SL, Choi KH, Park YH, Song HC, Kwon MS. Cemento-ossifying fibroma presenting as a mass of the parapharyngeal and masticator space. Am J Neuroradiol 1999; 20:1744-6.

11. Slootweg PJ. Maxillofacial fibro-osseous lesions: classification and differential diagnosis. Semin Diagn Pathol 1996; 13:104-12.

12. Firat Y, Firat AK, Karakas HM, Onal C. A case of frontal lobe abscess as a complication of frontal sinus ossifying fibroma. Dentomaxillofac Radiol 2006; 35:447-50.

13. Goh EK, Cho KS, Lee IW, Chon KM. A case of isolated ossifying fibroma of the mastoid cavity of the temporal bones. Am J Otolaryngol 2006; 27:358-61.

14. Koury ME, Regezi JA, Perrott DH, Kaban LB. Atypical fibro-osseous lesions: diagnostic challenges and treatment concepts. Int J Oral Maxillofac Surg 1995; 24:162-9.

15. Leimola-Virtanen R, Vähätalo K, Syrjänen S. Juvenile active ossifying fibroma of the mandible: A report of 2 cases. J Oral Maxillofac Surg 2001; 59:439-44. 